\title{
Epstein-Barr virus in carcinoma of the vulva
}

\author{
A N Y Cheung, U S Khoo, K Y Kwong, G Srivastava, R J Collins
}

\begin{abstract}
Aims-To detect the presence of Epstein-Barr virus (EBV) in cases of vulval carcinoma in Chinese patients living in Hong Kong.

Methods-Formalin fixed, paraffin wax embedded blocks from eight cases of vulval carcinoma and six age matched controls of non-neoplastic vulval tissue were analysed for the presence of EBV DNA using the polymerase chain reaction (PCR).

Results-EBV DNA was detected in only one of the eight cases of vulval carcinoma cases while it was detected in four out of the six control cases.

Conclusions-There is no demonstrable association between EBV and vulval carcinoma. Detection of EBV in nonneoplastic vulval epithelium highlights its ubiquitous presence in the lower female genital tract.
\end{abstract}

( Clin Pathol 1993;46:849-851)

The aetiological role of viruses in carcinoma of the lower female genital tract has been the focus of much research. The association between human papilloma virus (HPV) and cervical neoplasia is well known, although definitive proof of the causal role for this virus is still inconclusive. ${ }^{1}$ Moreover, HPV has also been detected in vulval squamous cell carcinoma. ${ }^{2}$ The role of synergistic carcinogenic factors such as two or more viruses interacting at different stages of carcinogenesis has been considered. ${ }^{3}$

Epstein Barr Virus (EBV) is an oncogenic herpes virus associated with certain $B$ cell lymphomas in humans and also with epithelial tumours such as nasopharyngeal carcinoma. ${ }^{4}$ EBV has also been found to replicate in cervical epithelium, and its possible role in the development of cervical carcinoma has been raised. 5 The association between EBV and vulval carcinoma, however, has not been

Pathology, University of Hong Kong, Hong

Kong

A N Y Cheung

K Y Kwong

G Srivastava

R J Collins

Correspondence to:

Dr Annie Cheung,

Department of Pathology,

University of Hong Kong,

Queen Mary Hospital,
Pokfulam Road, Hong

Kong.

Accepted for publication

5 May 1993

\section{Methods}

Eight cases of vulval carcinoma and six age matched control specimens of non-neoplastic vulval tissue were selected from the files of the Department of Pathology, University of Hong Kong. The age of the eight patients with vulval carcinoma ranged from 65 to 80 (mean 69.9). The age matched control group studied.

of patients were all Chinese and aged 70 or more. The histological slides were reviewed and the diagnosis confirmed. The tissue samples were then obtained from archival, formalin fixed, paraffin wax embedded blocks. Only tumour tissue or vulval epithelium in the control group was used for polymerase chain reaction (PCR) analysis. This was confirmed by histological examination of the sections adjacent to those used for DNA analysis.

For PCR analysis, two sections $16 \mu \mathrm{m}$ thick were cut from each sample and dewaxed. The genomic DNA was extracted using proteinase $\mathrm{K}$.

The oligonucleotide primers used for amplification of EBV spanned a region of 122 base pairs within the first internal repeat (IR1) of EBV DNA from base 1399 to 1520. The oligonucleotide reporter probe spans the intervening region within the first internal repeat (IR1) from base 1424 to 1439 (table).

Amplification for EBV DNA was carried out using the GeneAmp DNA amplification reagent kit with cloned Taq DNA polymerase (Perkin Elmer Cetus) using conditions reported before. ${ }^{6}$

The amplified products were analysed by gel electrophoresis in $4 \%$ NuSieve 3 in 1 agarose gel (FMC), followed by ethidium bromide staining.

The specificity of the amplified EBV DNA product was confirmed by Southern blotting of the gel, followed by probing of the membrane with ${ }^{32} \mathrm{P}$-labelled oligomeric reporter probe. The oligonucleotide reporter probe used was for the amplified BamH1 W region of the EBV genome (1424-1439).

DNA extracted from Burkitt's lymphoid cell line infected with EBV, Raji (ATCC, Maryland, USA), was used as a positive control and DNA from rat spleen tissue sections was used as a negative control.

On all samples negative for EBV DNA, analysis using human $\beta$ globin gene as an internal control was performed by PCR amplification followed by Southern blot. ${ }^{7}$
Sequences of oligonucleotide primers and probe used for the amplification of EBV DNA (5' $\left.\rightarrow 3^{\prime}\right)$

Primer $A$ : CCA GAG GTA AGT GGA CTT

(genomic location 1399-1417) Primer B: GAC CGG TGC C

Probe: TTC TGC TAA GCC CAA C 


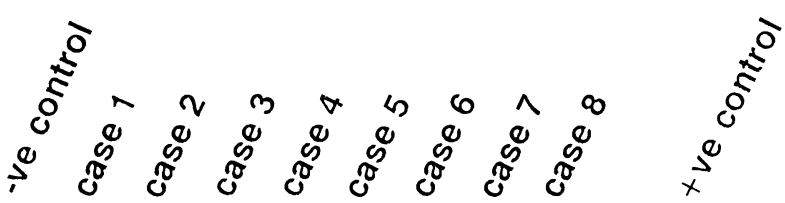

EBV

$122 \mathrm{bp}$

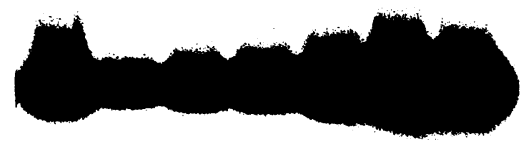

- Globin $110 \mathrm{bp}$

Figure 1 Results of the Southern blot hybridisation of the PCR products on vulval carcinoma for the detection of EBV DNA.

\section{Results}

Following amplification by PCR and Southern blot analysis of the amplified product, a weak signal for EBV DNA was detected in only one of the eight cases of vulval carcinoma cases (fig 1). EBV DNA was detected in four out of the six control cases (fig 2). Positive results following amplification of the $\beta$ globin gene was obtained in all the cases negative for EBV DNA.
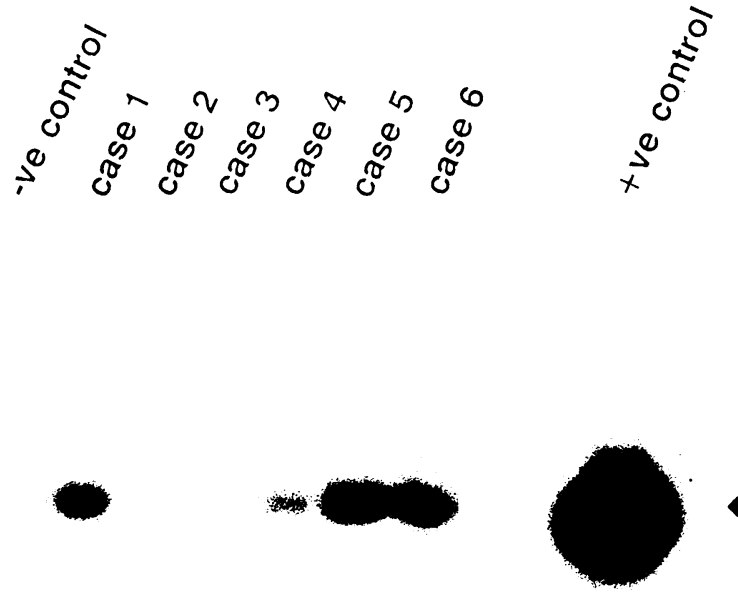

EBV

$122 \mathrm{bp}$

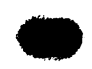

Globin

$110 \mathrm{bp}$

Figure 2 Results of the Southern blot hybridisation of the PCR products on non-neoplastic vulval tissue for the detection of EBV DNA.

\section{Discussion}

The role of viruses as aetiological agents in carcinoma of the lower female genital tract has been the focus of much interest but, to date, the evidence has been inconclusive. Researchers have postulated that two or more viruses are necessary and that these might interact at different states of carcinogenesis in cervical carcinoma. ${ }^{3}$

A carcinogenic role for $\mathrm{EBV}$ in the female genital tract has been suggested by the demonstration of EBV (C3D) receptors in normal cervical samples, ${ }^{58}$ and more recently, by the detection of EBV DNA in one out of three smears, using PCR and subsequent Southern blot, from patients with histologically confirmed epithelial abnormalities. ${ }^{9}$ The possibility has been raised that EBV could be sexually transmitted. ${ }^{5}$ In the cervix EBV replicates only in terminally differentiated epithelial cells ${ }^{10}$ and this may account for viral persistence without evident tissue destruction. It is thought that cellular events may be the decisive factor in determining whether the outcome is malignant transformation or lytic infection.

Detection of EBV DNA in four out of six $(66 \cdot 6 \%)$ cases of non-neoplastic vulval epithelium confirms the ubiquitous presence of this virus. Such persistence of virus in epithelial cells without serious destruction of tissue or clinically apparent disease is a feature of epithelial infection with other DNA viruses, such as cytomegalovirus (CMV) and human papillomavirus (HPV). ${ }^{4}$ This mechanism can provide a self sustaining reservoir of infection in the lower female genital tract. A similar study of cervical carcinoma done in our laboratory also showed a $44.5 \%$ incidence of EBV DNA detected in normal cervical tissue compared with a similar $48.8 \%$ incidence in cases of cervical carcinoma. ${ }^{11}$

Our study also showed, unusually, that EBV DNA is rare in vulval carcinoma, suggesting that EBV is probably not involved in the development of vulval carcinoma. Such findings are consistent with the observations obtained from a local study on cervical carcinoma ${ }^{11}$ mentioned above. In that study the prevalence of EBV DNA in the control group of non-neoplastic cervical tissue and the group of patients with invasive carcinoma of the cervix was the same. The finding of a lack of association between EBV and cancer of the lower female genital tract in Hong Kong is significant and contrasts with the known strong association between EBV and neoplasia in the upper respiratory tract in Hong Kong-namely, nasopharyngeal carcinoma. ${ }^{6} 12$ In situ hybridisation studies were performed using an EBER 1 and 2 probe for anti-sense RNA, but they failed to show any signal from any of the cases. The EBV DNA detected by PCR in the four control cases may have been below the detection level of in situ hybridisation techniques.

We conclude that EBV is not associated with vulval carcinoma. Moreover, the detection of EBV in non-neoplastic vulval epithe- 
lium highlights its ubiquitous presence within the lower female genital tract.

1 Arends MJ, Wyllie AH, Bird CC. Papillomaviruses and human cancer. Hum Pathol 1990;21:686-98.

2 Hording U, Daugaard S, Iversen AKN, Knudsen J, Bock JE, Norrild B. Gymecol Oncol 1991;42:22-6.

3 Zur Hausen H. Human genital cancer: synergism between two virus infections or synergism between a virus infection and initiating events. Lancet 1982;ii:1370-2.

4 Young LS, Sixbey JW. Epstein-Barr virus and epithelial cells: a possible role for the virus in the development of cervical carcinoma. Cancer Surveys 1988;7:507-18.

5 Sixbey JW, Lemon SM, Oagano JS. A second site for EBV shedding: the uterine cervix. Lancet 1986;ii:1122-4.

6 Dickens P, Srivastava G, Loke SL, Chan CW, Liu YT Epstein-Barr virus DNA in nasopharyngeal carcinoma
ENens from Chinese patients in Hong Kong. $\boldsymbol{\mathcal { J }}$ Clin Pathol 1992;45:396-7.
7 Saiki RK, Scharf S, Faloona F, et al. Enzymatic amplification of $\beta$-globin genomic sequences and restriction site analysis for diagnosis of Sickle cell anaemia. Science analysis for diagnosis

8 Sixbey JW, Davis DS, Young LS, Hutt-Fletcher L, Tedder TF, Rickinson AB. Human epithelial cell expression of an EBV receptor. $\mathcal{f}$ Gen Virol 1987;68: 805-11.

9 Bevan IS, Blomfield PI, Johnson MA, Woodman CBJ, Young LS. Oncogenic viruses and cervical cancer. Lancet 1989;i:907-8.

10 Sixbey JW, Davis DS, Young LS, Hutl-Fletcher L, Tedder TF, Rickinson AB. Human epithelial cell expression of an Epstein-Barr virus receptor. Clin Res $1986 ; 34: 533 A$.

11 Wong KY, Collins RJ, Srivastava G, Pittaluga S, Cheung ANY, Wong LC. Epstein-Barr virus in carcinoma of the ANY, Wong LC. Epstein-Barr virus in carcinoma of the

12 cervix. Int f Gynecol Pathol (in press). tion of Epstein-Barr virus markers in nasopharyngeal carcinoma patients. Oncology 1989;46:310-7. 